\title{
Comparison of the design rules for the end of the prestressed concrete double tee component between China and the United States
}

\author{
Xian Hong MENG ${ }^{1}$, Lu Xue ZHANG ${ }^{1, a}$ \\ ${ }^{1}$ Department of Civil Engineering, Shenyang Jianzhu University, Shenyang, China
}

\begin{abstract}
Precast prestressed concrete double tee is an economic bearing component which can be made into a large span, large coverage area .From the angle of the design for the end of the precast prestressed concrete double tee component, flexure and axial tension in extended end, direct shear, diagonal tension at re-entrant corner, diagonal tension in extended end and the connection of the end of precast prestressed double tee component in China and the United States are compared. The comparative studyprovide the direction for the future development of China in the double tee,including strengthening the end reinforcement and increasing end connections.
\end{abstract}

\section{Introduction}

Precast prestressed concrete double tee (hereinafter referred to as the double tee) is a pretensioned concrete element composed of two vertical precast beam and horizontal roof. Its cross section is a two " $\mathrm{T}$ " shaped, Precast prestressed concrete double tee is a prestressed reinforced concrete bearing structure, the high-strength prestressed reinforcement and high-strength lightweight concrete combined well, to improve the bearing capacity, reduce weight.

Double tee has simple shape with two high and narrow rib, a thin and widepanel, is a new type of environmentally friendly building materials is different with the traditional roof member, can be widely used in underground garage, industrial buildings, schools, hospitals and other large span building roof. Double T board itself has many advantages:

\subsection{Strong bearing capacity, light weight}

Double tee is beam plate combination, made of high-strength prestressed concrete and high-strength prestressed reinforcement. High strength prestressed reinforcement with high-strength lightweight concrete, not only can improve the bearing capacity of the component, reduce the weight, but also can effectively reduce the use of steel and concrete, reduce material costs, save cost, achieve economic applicable effect;

\subsection{Simple appearance, convenient construction}

Double tee has the cross section of double "T" type section, simple design, convenient construction, high construction speed, low material consumption and no large area of high formwork construction work,good economy, and can ensure the safety of construction process;

\subsection{The structure of good performance}

Compared with the steel structure, concrete frame, truss + roof panel, double tee structure has better comprehensive performance. The fire performance fire can reach grade two and above, good durability, good insulation properties, corrosion resistance, and rarely need maintenance. Compared with the traditional roof beam and roof panel system, double tee system has better overall performance, less welding, and has good aseismic performance. In addition, you can also save the indoor space.

Since Harry Edwards, the Americansdesign the first double tee with 2.4 mwidth and $15 \mathrm{~m}$ span in 1952 , double tee as a kind of economical type of precast concrete element, develop rapidly in the construction of industrial plants and large span buildings. The United States as the origincountry of the double tee, is the most widely used, especially in the large parking garage as floor. In Japan, the UK, Canada and other countries have also promoted the double tee, double tee has further development and improvement, and lay a solid foundationfor the future popular. Chinese understanding and research on the double tee began in the 60 's of last century, due to the production conditions and technical problems, the research on the double tee is mainly focused on the small span industrial plant. In the 70's of the last century, the main application of double tee was in electric power, oil field and other engineering, the maximum span of double tee was about $9 \mathrm{~m}$, it was flat, and then the standard design drawings SG432 was published. From the late 90's of last century so far, Daqing firstly transfer the study to large span industrial

${ }^{\mathrm{a} C}$ Corresponding author: 1316099859@qq.com 
building roof, and developed a double slope shape double tee products. April 1, 2014, the first precast concrete parking building project: assembled parking building of China first automobile group, FAW Group Technology Center in passenger car project began hoisting construction, so that the popularization and development of the double tee achieve a leap in the progress, become a landmark in the history of the development of double t. At present, the double tee is mainly used in industrial plants and large span civil buildings in our country.

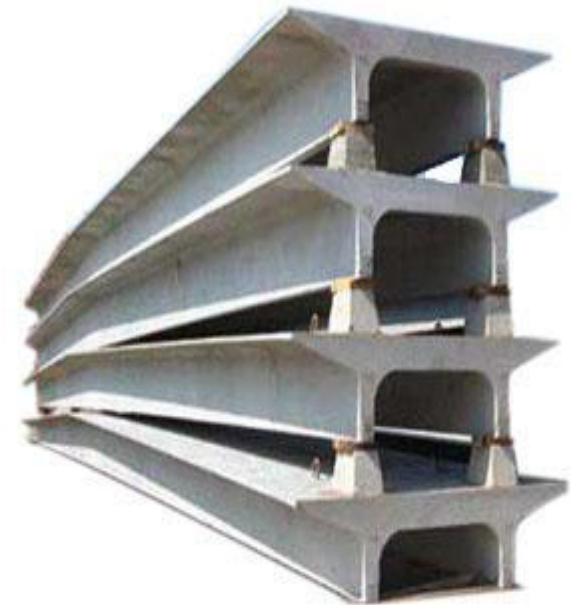

Figure 1.Double tee section in China

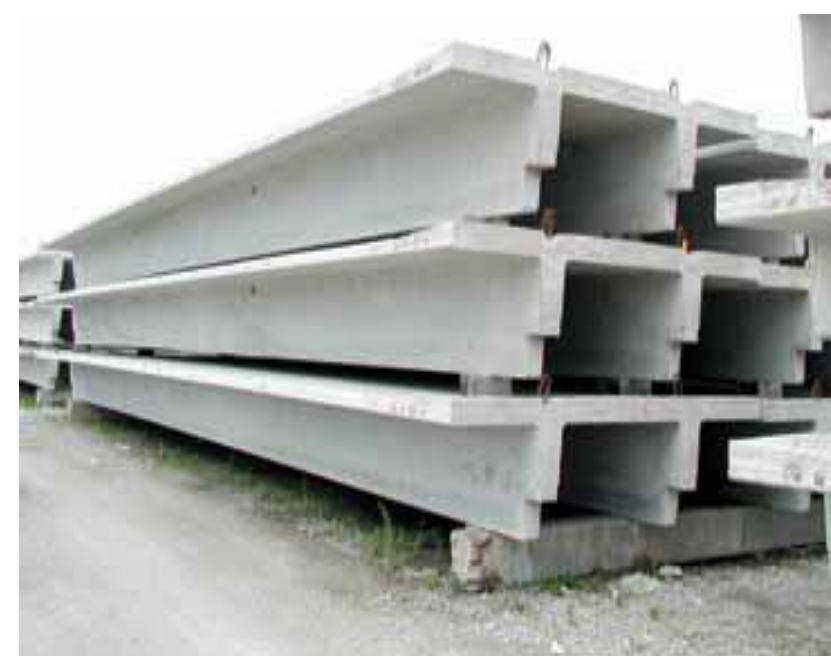

Figure 2.Double tee section in the United States

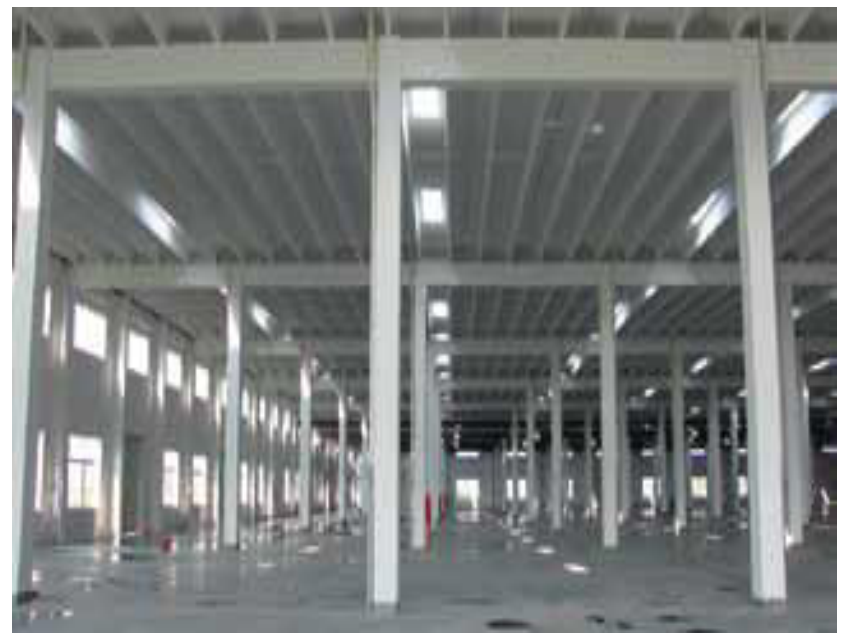

Figure 3.The application of double tee in China (a)

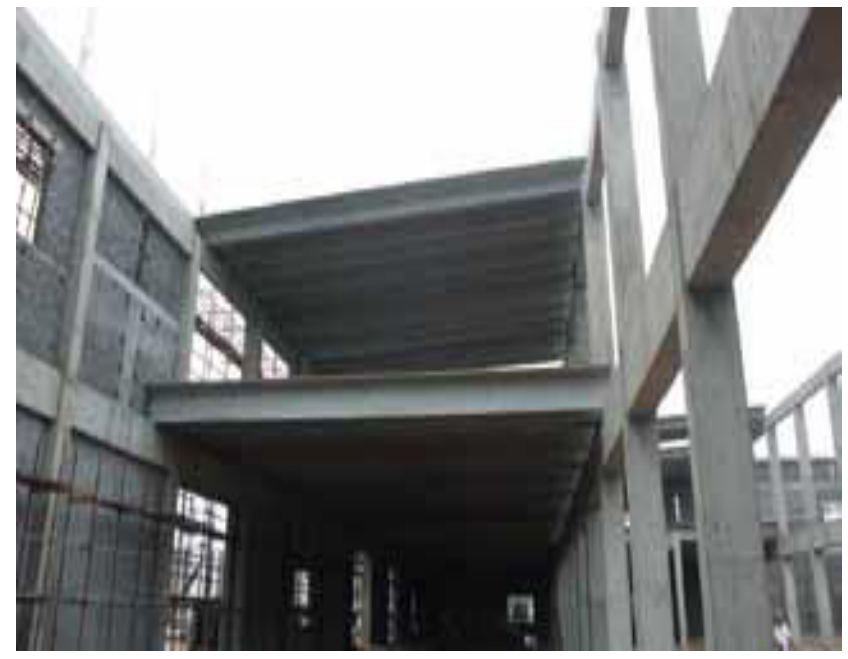

Figure 4. The application of double tee in China (b)

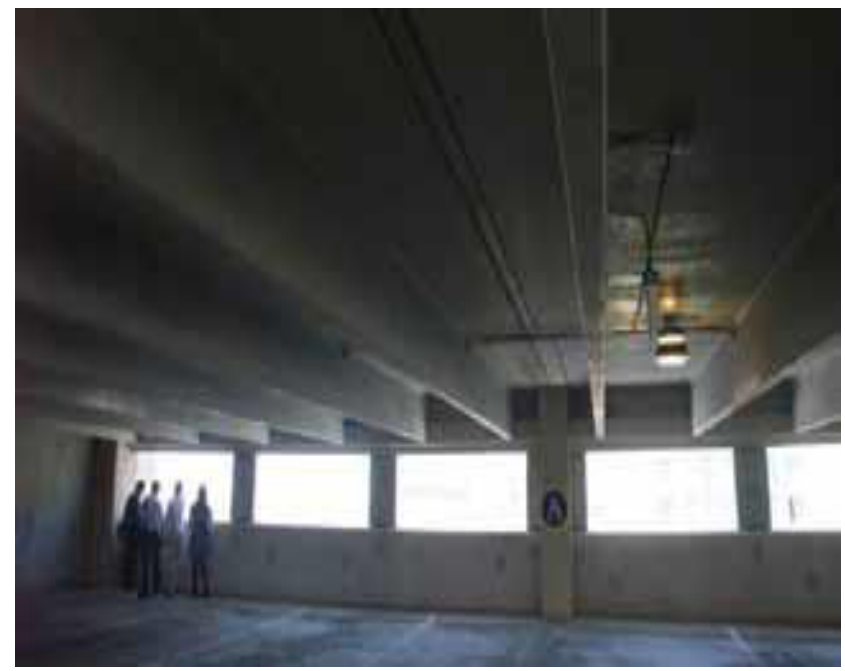

Figure 5.The application of double tee in the United States (a)

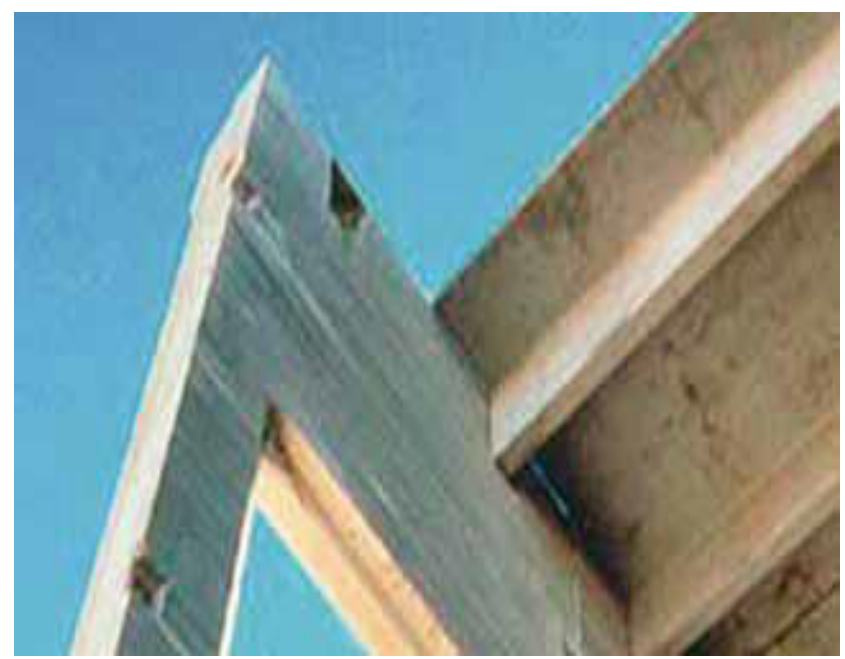

Figure 6. The application of double tee in the United State (b)

Compared to the United States, our country because of short development time, the limit of production technology, construction technology and production conditions, the study of double tee still belongs to the development of the 
state, still need to continue to learn. Based on few of domestic and foreign comparative study on design for the end of double tee component, the paper regard this as the starting point, the comparative study of the design for the end of double tee component, through the comparative study, find out the problems in double tee's design in China, and then improve the design of the double tee.

\section{Technical Standards}

In the 70's of the last century, China compiled the standard design atlas SG432. According to the local atlas and the engineering application experience, in 2006, the national building standard design drawings of the prestressed concrete double tee officially approved, a total of three, respectively 06SG432-1,09SG432-2,08SG432-3. So far, China has not yet issued special double tee product standards and technical regulations, in the engineering application person mainly refer to the national building standard design drawings.

The production and application of the double tee in the United States is mainly based on the PCI Design Handbook prepared by the Precast/Prestressed Concrete Institution. The design of the components in the PCI manual is mainly based on the concrete structure building code (318-05 ACI) and its provisions (318r-05 ACI). In addition, the load, section size, span and reinforcement amount are given in PCI manual, which provide the basis for the design and engineering application of precast and prestressed concrete components.

\section{Contrast of the End of Component}

\subsection{Component-end bearing}

In the United States, the end of double tee component often use the dapped-end, according to the PCI manual, calculate the dapped-end bearing .

Design of bearing areas that are recessed or dapped into the end of the component requires the investigation of several potential failure modes.

Dap reinforcement should be provided in all cases where any one or more of the following conditions occurs:

1. The depth of the recess exceeds $0.2 \mathrm{H}$ or $8 \mathrm{in}$.

2 . The width of the recess $\left(l_{p}\right)$ exceeds $12 \mathrm{in}$.

3a.For components less than 8 in. wide, less than one-half of the main flexural reinforcement extends to the end of the component above the dap.

3b.For components 8 in. wide or more, less than one-third of the main flexural reinforcement extends to the end of the component above the dap.

These criteria indicate that only short, shallow recesses, having the minimum amount of main reinforcement or more extending into the nib above the dap, do not require all the dap reinforcement. Experience and some unpublished tests verify that, for short, shallow recesses, the hanger reinforcement $A_{s h}$ and $A_{s h}^{\prime}$ is not necessary. However, in these cases, it is recommended that confinement reinforcement $A_{V}$ and flexural reinforcement $A_{v f}+A_{n}$.

The potential failure modes are as follows:

1. Flexure (cantilever bending) and axial tension in the extended end. Provide flexural reinforcement $A_{f}$ plus axial tension reinforcement $A_{n}$

2. Direct shear at the junction of the dap and the main body of the component. Provide shear-friction reinforcement composed of $A_{V f}$ and $A_{h}$, plus axial tension reinforcement $A_{n}$.

3. Diagonal tension emanating from the reentrant corner. Provide shear reinforcement $A_{s h}$.

4. Diagonal tension in the extended end. Provide shear reinforcement composed of $A_{h}$ and $A_{V}$.

5. Diagonal tension in the undapped portion. This is resisted by providing a full development length for $A_{S}$ beyond the potential crack.

Each of these potential failure modes should be investigated separately. The reinforcement requirements are not cumulative, that is, $A_{S}$ is the greater of that required by 1 or 2 , not the sum. $A_{h}$ is the greater of that required by 2 or 4 , not the sum.

Detailed calculation can be seen in PCI manual.

China double tee end is flat-end, rarely involved in the end of the gap type. The position of double tee of the flat-end is generally at the top of the support member, the design calculation is relatively simple. For the calculation of the dapped-end, the standard GB50010-2010 of our country has not yet provided the corresponding calculation standards, and the lack of relevant design basis.

\subsection{Component-end Connection}

According to national building standard design drawings "Prestressed Concrete Double Tee", the end of double teecomponent is the whole section, the end of the rib beam mainly connect by welding. Specific connection mode can be seen in the Chinese Atlas "Prestressed Concrete Double Tee." And thedouble tee component-end connection style in the United States not only include Chinese connection style, but also put the binding bolt (on top of the end plate and welding combined to connect. Thus, compared with the component-end connection of double tee with the UnitedStates,component-end connection in China is relatively single, we can learn from the successful experience of the United States.

\section{Conclusions}

According to study on the difference from flexure and axial tension in extended end, direct shear, diagonal tension at re-entrant corner, diagonal tension in extended end and the connection of the end of precast prestressed double tee component in China and the United States, we can discover that the design for the end of precast 
prestressed concrete double tee component is still flawed,China national building standard design drawings"Prestressed Concrete Double Tee" should be revised to make it more perfect.

\section{Acknowledgements}

This work was financially supported by the Project of National Key Technology R\&D Program in the12th Five Year Plan of China (2011BAJ10B04).

\section{References}

1. China Construction Science Research Institute.06SG432-1prestressed concrete double tee (slope board, width 2.4m) [S]. Beijing: China Planning Press, 2006

2. China Construction Science Research Institute.08SG432-3 prestressed concrete double tee (slope board, width $3.0 \mathrm{~m}$ ) [S]. Beijing: China Planning Press, 2008

3. China Construction Science Research Institute.09SG432-2 prestressed concrete double tee (slab, width $2.0 \mathrm{~m}, 2.4 \mathrm{~m}, 3.0 \mathrm{~m}$ ) [S]. Beijing: China Planning Press, 2009

4. MaoyuWang. Comparison of precast prestressed concrete double tee components between China and America [J]. Concrete and cement products, 2014, (8): 42-45

5. Precast/Prestressed Concrete Institute. PCI Design Handbook [M].7th Edition.Chicago,IL,2010.

6. QiongLiu. Research and application of precast concrete structures $[\mathrm{J}]$. construction technology, 2014, (22): 09-14

7. Xiaofeng Wang, Yong Zhao.Application and technique of prestressed concrete double tee [J].The second session of the forum of industrialization of construction technology,2012,98-103

8. Wuhua Tang, Tao Qiu. Design analysis of prestressed concrete double tee $[\mathrm{J}]$. Building structure, 2009,(39),58-59

9. Rui Pang, Shuting Liang. Study on precast concrete double tee floor system abroad[J].Industrial buildings 2011, 41(3), 12-126

10. Fenggang Jiang, Chengwu Chen. Application analysis of large span prestressed concrete double $\mathrm{T}$ slab construction[J].Journal of Qingdao Technological University. 2014, 35(6), 36-39 